\title{
LA GESTIÓN DE NEGOCIOS COMO OBLIGACIÓN EN EL DERECHO ROMANO Y SU REGULACIÓN COMO “CUASI EX CONTRACTU” EN EL CÓDIGO CIVIL COLOMBIANO
}

\author{
José Alexander Ávila Vallecillo ${ }^{1}$
}

DOI: https://doi.org/10.5377//rd.v42i1.12942

"Obligatio est juris vinculum quad necessitate adstringimur alicujus sonvendae vei secundum nostras civitatis jura".

(La obligación es un vínculo jurídico que necesariamente constiñe a hacer algo a favor de otra según las leyes de nuestra ciudad)

\section{RESUMEN:}

Durante mucho tiempo se creía que la figura de la Gestión de Negocios era considerablemente nueva, que nada tenía que ver con el Derecho romano antiguo, siendo esta, una concepción errónea en la que cualquier jurista o profesional del derecho podría incurrir, puesto que la mayoría de codificaciones latinoamericanas están íntimamente inspiradas en dicha institución, siendo la negotiorum gestorum una verdadera fuente de obligaciones.

En el ejercicio de mis funciones como Registrador de Instrumentos Públicos, me vi en la tarea de conocer y a la vez calificar diversos tipos de contratos, tanto mercantiles como civiles, siendo para ello el más recurrente el contrato de compraventa de bienes inmuebles.

No obstante, pude observar que a lo interno de ciertos testimonios de compraventa, un Gestor Oficioso (negotiorum gestor) actuaba como adquirente en nombre y representación de otro que se encontraba ausente (dominus), pero que jurídicamente adquiría los derechos y obligaciones producto de esa relación contractual.

Así la cosas, el conflicto jurídico se generaba ante nuestras oficinas cuando a contrario sensu, ese gestor oficioso comparecía en su condición de vendedor, transfiriendo los derechos y obligaciones que de ese inmueble le pudieran corresponder no a éste, sino al dueño del mismo, para lo cual procedíamos a denegar provisionalmente su inscripción, fundamentándonos en el argumento de que dicha figura legal aplicaba únicamente cuando se adquirían derechos u obligaciones a favor del original dueño, no así para transferir los mismos.

\footnotetext{
1 Magister en Derecho con énfasis en Derecho Mercantil, contratos y negocios Internacionales. Docente Titular en la Facultad de Ciencias Jurídicas, Universidad Nacional Autónoma de Honduras. Instituto de Investigación Jurídica UNAH, Edificio 5, Planta baja, Correo Electrónico: jaavhn@yahoo.com

2 Justiniano I el Grande. (Flavius Petrus Sabbatius Justinianus) Emperador bizantino (Tauresio, Macedonia, 482 Constantinopla, 565).
} 
Otro considerando en que fundamentábamos la denegatoria, versaba en que, para tener por válida dicha venta, se requería de un poder especial (mandato) en la que se facultara al susodicho Gestor para consolidar la venta del inmueble, a nombre y representación del legítimo propietario.

Es evidente que muchos profesionales y notarios en general, tienden a confundir los derechos y obligaciones emanados de la gestión de negocios en analogía con las del mandato propiamente dicho, y aunque existen algunas similitudes, las diferencias entre ellas son considerablemente abismales.

El Código Civil Colombiano regula la gestión oficiosa o gestión de negocios ajenos del artículo 2304 al 2312, estableciendo para ello definiciones conceptuales y diferentes parámetros jurídicos que reglamentan esta figura generadora de obligaciones.

De lo anterior cabe preguntarse si en realidad, la figura de la Gestión de negocios era utilizada en el Derecho Romano de igual forma, es decir, para adquirir derechos y obligaciones a beneficio del ausente y no para transferir los mismos.

Justiniano revela como una obligación posee la capacidad jurídica para exigir a las partes contratantes y consumar así una acción en pro o a favor de otra, amparándose en las codificaciones propias de un país o región determinada, prevaleciendo en el pensamiento inicialmente citado, principios como el de legalidad y buena fe.

Finalmente, se torna justo y necesario ahondar y a la vez profundizar en aquellos elementos que obligan y abrazan tanto al gestor de negocios ajenos, como también al dueño de ese negocio jurídico y conocer así el génesis fundamental que fortaleció dicha figura legal en el derecho romano.

PALABRAS CLAVE: Gestión oficiosa, estipulación, Código Civil, Derecho Romano, Cuasicontrato, mandato

Fecha de recepción: 31/8/21

Fecha de aprobación: 24/11/2021 


\title{
BUSINESS MANAGEMENT AS AN OBLIGATION IN ROMAN LAW AND ITS REGULATION AS" QUASI EX CONTRACTU “IN THE COLOMBIAN CIVIL CODE
}

\author{
José Alexander Ávila Vallecillo ${ }^{3}$
}

DOI: https://doi.org/10.5377//rd.v42i1.12942

\begin{abstract}
"Obligatio est juris vinculum quad necessitate adstringimur alicujus sonvendae
vei secundum nostras civitatis jura

The obligation is the bond of law which binds us by necessity

or according to the laws of our state
\end{abstract}

\begin{abstract}
ABTRACT:
For a long time it was believed that the figure of the Business Management was considerably new, that it had nothing to do with the ancient Roman Law, being this, a wrong conception in which any jurist or professional of the law could incur, since the majority of Latin American codifications are intimately inspired in this institution, being the negotiorum managerum a true source of obligations.
\end{abstract}

In the exercise of my duties as Registrar of Public Instruments, I found myself in the task of knowing and qualifying various types of contracts, both commercial and civil, the most recurrent being the contract for the sale of real estate.

However, I was able to observe that within certain testimonies of sale and purchase, an Official Manager (negotiorum gestor) acted as purchaser on behalf and representation of another who was absent (dominus), but who legally acquired the rights and obligations arising from that contractual relationship.

Thus, the legal conflict was generated before our offices when, in the opposite direction, that informal manager appeared in his capacity as a seller, transferring the rights and obligations of that property that might correspond not to him, but to the owner of the same, for which we proceeded to provisionally deny its registration, based on the argument that this legal figure applied only when rights or obligations were acquired in favor of the original owner, not to transfer them.

Another consideration on which we based our refusal was that, in order to consider such sale valid, a special power of attorney (mandate) was required in which the Manager was authorized to consolidate the sale of the property, in the name and on behalf of the legitimate owner.

3 Master in Law with an emphasis on Commercial Law, contracts and International business. Professor at the Faculty of Legal Sciences, National Autonomous University of Honduras. UNAH Legal Research Institute, Building 5, Ground Floor,

Email: jaavhn@yahoo.com 
It is evident that many professionals and notaries in general, tend to confuse the rights and obligations arising from the management of businesses in analogy with those of the mandate itself, and although there are some similarities, the differences between them are considerably abysmal.

The Colombian Civil Code regulates the informal management or management of other people's businesses from article 2304 to 2312, establishing conceptual definitions and different legal parameters that regulate this figure generating obligations.

From the above, it is worth asking if in reality, the figure of the Management of business was used in Roman Law in the same way, that is, to acquire rights and obligations for the benefit of the absent and not to transfer them.

Justiniano reveals how an obligation has the legal capacity to demand from the contracting parties and thus consummate an action for or in favor of another one, protecting itself in the own codifications of a certain country or region, prevailing in the initially mentioned thought, principles like the one of legality and good faith.

KEYWORDS: Informal management, stipulation, Civil Code, Roman Law, Quasi-contract, mandate

Date received: $8 / 31 / 21$

Approval Date: 11/24/2021 


\section{INTRODUCCIÓN}

Ante el inminente desconcierto entre la gestión de negocios y el mandato propiamente dicho, se torna justo y necesario realizar una diferenciación entre ambas figuras jurídicas.

En el Derecho romano, "Las obligaciones nacidas de este cuasicontrato (negotiurum gestium) eran parecidas a las del mandato ${ }^{4}$

En páginas anteriores nos hemos encargado de conceptualizar la figura de la gestión de negocios, sin embargo, nos enfocaremos en esta parte a definir el concepto que gira en torno al mandato y a establecer diferencias.

El mandato en el derecho romano es un "contrato simplemente consensual, sinalagmático imperfecto, y de buena fe, por el cual una persona encargaba a otra que aceptaba, la realización gratuita de una o más operaciones que tuvieran un interés pecuniario para el mandante ${ }^{5 "}$.

El mandato "es un contrato por el cual una persona da encargo a otra persona, que acepta, de realizar gratuitamente un acto determinado o un conjunto de operaciones" ${ }^{6}$

En nuestra legislación Civil colombiana un mandato se define, "como un contrato en que una persona confía la gestión de uno o más negocios a otra, que se hace cargo de ellos por cuenta y riesgo de la primera" ${ }^{7 "}$.

4 Lecciones de Derecho Romano, Carlos J. Medellín, Carlos Medellín F., Decimocuarta edición, Editorial Temis, S.A, Sata Fe de Bogotá, Colombia, 2000, Página No 263.

5 Lecciones de Derecho Romano, Carlos J. Medellín, Carlos Medellín F., Decimotercera edición, Editorial Temis, S.A, Sata Fe de Bogotá, Colombia, 1997, Página No 258.

6 Mandatum viene de manum dare, dar la mano en señal de confianza y, por extensión, dar poder (Plauto, Captiv. Act. II, SC. 3)

7 Código Civil Colombiano, Versión Actualizada, Legis Editorial,
A medida que avanzamos en el presente estudio, nos damos cuenta que la gestión de negocios tiende a ser confundida con la figura del mandato.

Tal y como lo relacionábamos en la introducción del presente trabajo investigativo, ante nuestras oficinas registrales ingresaban testimonios de escrituras públicas en donde un gestor comparecía en algunas ocasiones, aceptando y en otras, otorgando en venta un inmueble a favor de un tercero (comprador).

Cuando un gestor aparecía en calidad de otorgante o vendedor, procedíamos a denegar el registro de dicha venta, amparados en que, el compareciente que actuaba como gestor no debía aparecer como tal, sino como representante del legítimo dueño, requiriendo para ello un poder (mandato) en donde se le confirieran amplias facultades para administrar sus negocios y consumar así dicha venta.

Podemos observar que las obligaciones nacidas de la gestión de negocios, tienden a ser confundidas con la figura del mandato, sin embargo es claro que en la gestión no existe consentimiento alguno, mientras que en el mandato si lo hay.

De conformidad a lo regulado en el derecho romano, un gestor podría actuar en tal condición, siempre y cuando la adquisición del inmueble objeto de venta sea de utilidad y beneficio para el dominus, de lo contrario éste podría ejercitar la acción de negotiorum gestorum directa contra éste, sin embargo para que un gestor pueda otorgar en venta dicho inmueble, no cabría dicha figura, requiriendo para ello un mandato especial, en donde se le faculte, no como gestor sino más bien como mandatario a efectuar esa venta.

2010, Bogotá, Colombia, articulo 2142. 
En cuanto a los compromisos desencadenantes entre ambas figuras jurídicas, El Código Civil Colombiano establece en su artículo 2305, que "las obligaciones del agente oficioso o gerente son las mismas que las del mandatario".

Por su parte, el Código de comercio colombiano es otra compilación en donde se contempla a la gestión de negocios como figura legal (artículo 235), y por ende existe un ligero riesgo de ser confundida con la Fiducia mercantily el mandato propiamente dicho, siendo la "fiducia un negocio jurídico típico bien distinto del mandato y por ello el fiduciario obra en nombre propio comprometiendo los bienes afectados sin que sus actos se puedan entender como realizados por cuenta de otro ${ }^{8 "}$.

Según, Arias García "la expresión "por cuenta de otro" no tiene asidero en la gestión fiduciaria porque ésta no implica un fenómeno representativo y está bien alejada de figuras como la estipulación para otros, la estipulación por otros, la gestión de negocios y el mandato" de conformidad con el artículo 1235 del Código de Comercio Colombiano". ${ }^{43}$

Claro está que las obligaciones emanadas entre gestión de negocios y mandato son inmediatamente vinculantes, sin embargo, ambas figuras se diferencian una de la otra en que, en la gestión no hay consentimiento por parte del dueño, mientras que en el mandato si existe dicho consentimiento como tal, sea éste expreso o tácito.

\section{METODOLOGÍA}

En el desarrollo de esta investigación se aplicó un estudio analítico argumentativo pues se buscó 8 El Fiduciario en la Legislación Mercantil Colombiana, Fernando Arias García, Revista Internauta de Práctica Jurídica. Núm 20 Julio Diciembre 2007, Pág. 2. analizar y revisar los códigos civiles de Honduras y Colombia, siendo que ambos sistemas poseen un mismo origen doctrinal y legal. Se realizó además una exhaustiva revisión de diferentes fuentes bibliográficas nacionales e internacionales en torno a la figura de la Gestión Oficiosa creada por los antiguos romanos.

Se desarrolló para ello, una investigación de tipo descriptiva y documental, asimismo se utilizó el método teórico inductivo y analítico puesto que se procuró brindar una respuesta a la aplicación e implementación de la gestión oficiosa como una figura jurídica antigua, utilizada para originalmente para adquirir derechos, no así para transferir los mismo.

Aparejadamente se recurrió al método de estudio comparado puesto que se analizaron diversos contextos jurídicos nacionales e internacionales.

\section{ASPECTOS HISTÓRICOS}

Algunos estudiosos del Derecho romano aseguran que la Gestión de Negocios "nace, en materia procesal, para representar al ausente citado a juicio. Posteriormente se amplía su contenido a los bienes y actuaciones patrimoniales, para culminar en la intervención voluntaria, sin mandato ni representación legal, en el patrimonio de otro". ${ }^{9}$

De Semo, asegura que la fecha más asequible en que se hizo necesario el edicto De negottis gestis surge del documento más antiguo de él y "proviene del Jurisconsulto Quinto Mucio Scaevola, que fue cónsul en el 659 de la ciudad, y murió en 1672 (182 años antes de Cristo); de

9 Gestión de Negocios, Alicia M. Oviedo Bustos, Editorial Astrea, Primera Edición 1984, Lavalle, Buenos Aires, Argentina, Página número 8. 
donde parece fundada la conjetura de que las causas determinantes de la publicación del edicto pretorio remontan a tiempo no muy anterior, y que, por tanto, la fecha del mismo puede establecerse entre el sexto y séptimo siglo de Roma"10.

Como podemos apreciar, el espíritu que inspiró y a la vez creó la figura jurídica de gestión de negocios en el derecho romano, fue la defensa de aquellas personas que en algún momento se encontraban ausentes por alguna u otra razón, en un tiempo o espacio determinado.

Por esa razón es que Ulpiano afirma que "este edicto es necesario, porque redunda en gran utilidad de los ausentes. ${ }^{11}$

El requisito de la ausencia en la gestión de Negocios es justificado por algunos doctrinarios, "por la expansión debida a conquistas territoriales, luchas intestinas por la que los vencidos debían huir basados en motivos de seguridad personal, además podía suceder que alguien se ausentase con idea de un pronto regreso que por diversas causas no pudiera hacerlo". ${ }^{12}$

Por su parte Gayo manifiesta: "Mas esto se admitió así porque muchas veces los hombres salen de viaje con la intención de volver inmediatamente y por esto no encomiendan a ninguno el cuidado de sus propios negocios, y después, mediando nuevas causas, están ausentes por necesidad, más largo tiempo, y era injusto que

10 De Semo Giorgio, La Gestión de Negocios Ajenos en la teoría y en la práctica, tr. J. Rodríguez del Barco, Madrid, Revista de Derecho privado, 1961, Página 11.

11 Digesto, Libro III, tit. V. Ley I. García del Corral Ildefonso, cuerpo del derecho civil romano, traducido al castellano del latín, publicado por los hermanos Krieguel, Hermman Osenbruggen, Barcelona Jaime Molinas, 1889.

12 De Semo Giorgio, La Gestión de Negocios Ajenos en la teoría y en la práctica, tr. J. Rodríguez del Barco, Madrid, Revista de Derecho privado, 1961, Página 10-11. se perdieran sus negocios; los que ciertamente perdería, ya si el que se hubiera ofrecido para administrar los negocios no hubiese de tener ninguna acción por lo que últimamente hubiese gastado de lo suyo ya si aquel cuyos negocios hubiesen sido administrados no pudieran ejercitar ningún derecho contra el que se hubiese entrometido en sus negocios"13

No obstante, la misma se aplicaba de igual formaencasosdeignoranciadeundueñopresente ${ }^{14}$.

En las Institutas, aparece la definición de Gestión y su regulación de la manera siguiente:

“1) Así, pues, cuando alguno hubiere administrado los negocios de un ausente, nacen entre ellos de una y otra parte acciones, que se llaman negotiorum gestorum (de gestión de negocios). Pero al dueño de la cosa administrada le compete verdaderamente la acción directa contra aquél que la administró, y al administrador de los negocios, la contraria. Cuyas acciones es evidente que no nacen propiamente de ningún contrato, porque nacen estas acciones si alguno sin mandato se hubiera ofrecido a cuidar de los negocios de otro; por cuya causa, aquellos cuyos negocios hubieren sido administrados se obligan aun sin saberlo.

Y esto se admitió por razón de utilidad, para que los negocios de los ausentes que obligados por una súbita urgencia, y sin haber encomendado a nadie la administración de su negocio, hubiesen salido de viaje, no quedarán abandonados, pues de tales negocios nadie habría ciertamente de

13 El Digesto de Justiniano, Tomo III, Version Castellana por A. D'ors, F. Fernando-Tejero, Fuenteseca, M. García-Garrido y J. Burillo, Libro XLIV, tit. VII. Ley 5, Editorial aranzadi, Pamplona, páginas 474-475.

14 El Digesto de Justiniano, Tomo I, Libro III, tit. V, Leyes 41 y 48. 
cuidar, sino hubiera de tener ninguna acción por aquello que hubiese gastado. Pero así como el que últimamente hubiese administrado negocios tiene obligado al dueño de los negocios, así también por el contrario está también el obligado a rendir cuentas de su administración, en cuyo caso es compelido a rendir cuentas, hasta por la más exacta diligencia, y no basta que ponga tanta diligencia cuanta acostumbra a poner en sus cosas, siempre que otro más diligente hubiera administrado mejor los negocios" ${ }^{\prime 15}$

Por su parte, la gestión en favor de otro , "inferida por consideraciones objetivas en el derecho clásico, se hizo depender en la compilación de la voluntad (animus aliena negotia gerendi); al igual que le período clásico, el gestor debía llevar a cabo la gestión a pesar de la muerte del beneficiario (D. 3, 5, 20[21], 22, 2); y aunque en el período procedente las acciones de la gestión de negocios protegían los derechos del tutor y el curador al resarcimiento, estas fueron suplantadas por la de la tutela contraria y la utilis curationes causa actio (D. 27, 3), respectivamente ${ }^{16 ”}$.

La Agencia oficiosa o gestión de negocios (negotiorum gestio), "ha sido negada por los romanistas del derecho clásico romano, sin embargo su importancia para el concepto contemporáneo del enriquecimiento sin causa es suficientemente importante como para resumir sus características en el derecho bizantino ${ }^{17}$ ".

Finalmente, podríamos decir que la Gestión de Negocios en el Derecho Romano surgió por causa de utilidad, para que las personas que

15 Institutas, Libro III, tit. XXVII, Ley I. .

16 Historia del Derecho Romano, Fabio Espitia Garzón, Tercera edición, Universidad Externado de Colombia, Bogotá, Colombia, Página 378-379.

17 Curso de Derecho Romano, Eduardo Álvarez Correa, Primera edición, Editorial Puma Ltda, Bogotá, Colombia, 1979, Página 481.

192| Revista de Derecho. Vol. 42, No. 1, Año 2021 debían ausentarse por alguna u otra razón y con urgencia lo pudieran hacer, sin que para ello fuese necesario encomendar a otra persona la administración expresa de sus negocios.

\section{CONCEPTO Y DEFINICION DE LA GESTION DE NEGOCIOS}

Previo a entrar en materia, se hace imprescindible definir la figura de la Gestión oficiosa, y de la manera en que ésta era concebida por aquellos personajes romanos que la inspiraron y consolidaron.

En el título XXVI de las Instituciones de Justiniano, se efectúa el siguiente planteamiento: "cuando alguno ha desempeñado negocios de un ausente, nacen por una y otra parte acciones llamadas negotarium gestorum, acción directa para aquel cuyo negocio ha sido desempeñado contra el gerente, y acción contraria para éste último" ${ }^{18}$.

Claro está que las obligaciones resultantes de la gestión de negocios no deriva de un contrato propiamente dicho, sino más bien de un cuasicontrato, en donde el gestor se introduce en los negocios de otro (dueño) sin mandato alguno, quedando obligado de manera automática, sin saber que lo está.

Así la cosas, el derecho Justinianeo califica de "acciones directas a aquellas acciones personales que normalmente surgen de un contrato o situación jurídica contra el sujeto que en virtud de los mismos aparece como principal obligado: ejemplo, actio mandati directa contra el mandatario, negotarium gestorum directa contra el gestor de negocios ajenos ${ }^{19}$ ".

18 Instituciones de Justiniano, Edición Bilingüe, Con una nota previa sobre Justiniano y las Institutas, por M. Ortolán, profesor de la facultad de derecho de París, Editorial Heliasta S.R.L., Buenos Aires Argentina, Titulo XXVII, Pág. 275.

19 Instituciones de Derecho privado Romano, Caramés Ferro,

ISSN: 2509-5296 (Impreso) 
Gayo por su parte, hace una sutil diferencia entre gestión y hecho al aseverar que "aunque entre gestionado y hecho parece que hay cierta sútil diferencia, no hay sin embargo, por abuso ninguna diferencia entre hecho y gestionado" ${ }^{20}$.

Lo anterior hace referencia a las fuentes de origen de las mismas, es decir, si la tutela tenía una procedencia civil o resultaba de una potestad judicial.

Según Alicia M. Oviedo, estima que en el "Derecho romano y en el derecho civil clásico se consideraba que la gestión de negocios era una de las figuras integrantes de los llamados cuasicontratos, y que ésta existe cuando una persona interviene espontánea o voluntariamente, esto es sin obligación voluntaria o legal alguna, en los negocios de otra" 21 .

Según Lucrecio Jaramillo Vélez, la figura de Gestión de Negocios es "una relación original, genuinamente romana y sin paralelo en los derechos de otros pueblos que no deriven del romano. Es un producto de las humanistas romana y la idea que la inspira es la que de que un hombre debe ayudar siempre a sus semejantes, cuando estos necesitan ayuda. Nadie está jurídicamente obligado a cuidar los bienes de otro, pero el derecho de favorecer y facilitar esta acción altruista, garantizando al gestor el derecho a exigir el reembolso, lo que supone, por otra parte, también una responsabilidad para del gestor ${ }^{22}$ "

José M., Bs. As., Perrot, 1953, Buenos Aires Argentina, Página 338. 20 El Digesto, Libro L, tit, XVI, Ley 58.

21 Gestión de Negocios, Alicia M. Oviedo Bustos, Editorial Astrea, Primera Edición 1984, Lavalle, Buenos Aires, Argentina, Página número 8.

22 Historia del Derecho Romano, Sistema de Derecho Privado, Lucrecio Jaramillo Vélez, Cuarta Edición, Señal Editora, 1986, Página 240.
En el Derecho Romano antiguo se "decía que una obligación que nacía quasi ex contractu, cuando la fuente de ella no estaba en el acuerdo de voluntades de dos o más personas contratantes, sino en la consumación de determinados actos civiles lícitos que producían efectos análogos a los de un contrato" 23 .

La agencia oficiosa "es un acto o hecho de una persona, el agente, en beneficio de un tercero sin la autorización de éste.” ${ }^{24}$.

Otros consideran que hay gestión de negocios "cuando una persona administra voluntariamente los negocios ajenos, sin habérselo encargado" ${ }^{25}$.

Finalmente el artículo 2,304 del Código Civil Colombiano define a la agencia oficiosa o gestión de negocios ajenos, "como un contrato (sic) por el cual, el que administra sin mandato los bienes de alguna persona, se obliga para con ésta, y la obliga en ciertos casos" 26 .

Como podemos observar, las diferentes concepciones de la Gestión de Negocios, redundan en que ésta es un acto voluntario a beneficio de un tercero, y sin la autorización expresa del dueño del negocio.

\section{PARTES INTERVINIENTES EN LA GESTION DE NEGOCIOS}

23 Lecciones de Derecho Romano, Carlos J. Medellín, Carlos Medellín F., Decimotercera edición, Editorial Temis, S.A, Sata Fe de Bogotá, Colombia, 1997, Página No 235.

24 Curso de Derecho Romano, Eduardo Álvarez Correa, Primera edición, Editorial Puma Ltda, Bogotá, Colombia, 1979, Página 481

25 Tratado Elemental de Derecho Romano, Eugene Petit, Editorial Albatros, 1985, Buenos Aires Argentina, Pág. 570.

26 Código Civil Colombiano, Versión Actualizada, Legis Editorial, 2010, Bogotá, Colombia.

Revista de Derecho. Vol. 42, No. 1, Año $2021 \mid-193$ 
De conformidad a nuestro Código Civil, al que interviene en el negocio de otro se le denomina Gerente, mientras que a favor de quien se efectúa el negocio se le llama, Dueño.

En resumen las partes intervinientes son:
a) El Gerente o negotiorum gestor; y
b) El dueño o Dominus.

\section{FUENTE DE OBLIGACIONES}

La gestión de negocios como un cuasicontrato, se asemeja a un contrato propiamente dicho, en que ambos generan obligaciones y traen consigo hechos semejantes o parecidos, sin embargo se diferencian el uno del otro, en que los cuasicontratos carecen un elemento consensual (consentimiento).

Luis Alfonso Muñoz, asegura que la Agencia oficiosa o gestión de negocios "surge como una institución del derecho pretoriano, con aplicación a la administración de negocios del ausente, sin su consentimiento, pero con la intención de crear obligaciones recíprocas, así: para el gestor, la obligación de realizar o administrar los bienes hasta su cumplimiento total, y para el administrado la de reconocer los gastos causados en su provecho". ${ }^{27}$

Gayo considera a la "gestión de negocios ajenos, la tutela, las obligaciones de los comuneros y coherederos, el heredero en relación de las deudas derivadas del legado y el pago de lo no debido, considerados en los Libri rerum cottidianarum o Res cottiidianae, como fuentes de obligaciones derivadas de otras figuras (variis causarum figuris), que fueron agrupadas por los compiladores en el elenco de los cuasicontratos" 28

27 Derecho Romano comparado con el derecho colombiano, Luis Alfonso Muñoz López, Quinta edición, Editorial Temis S.A., Bogotá, Colombia, 2007, Página número 262.

28 Historia del Derecho Romano, Fabio Espitia

\section{VII.TIPOLOGIAS DE GESTION OFICIOSA ROMANA}

Existen variadas tipologías y diversas clasificaciones de negotiarum gestorum, sin embargo nos enfocaremos en las más recurrentes y en las más utilizadas en el sistema jurídico romano.

En cuanto a cuasicontratos se refiere, el derecho romano promulgaba "que la obligación permanecía en estos casos como de un contrato. Las principales fuentes de estas obligaciones eran según las instituciones de Justiniano, las siguientes: 1) La Negotarium Gestio; 2) La indivisíon 3) La Aceptación de una herencia; 4) La tutela o curaduría; y 5) El Pago de lo no debido ${ }^{29}$ "

Otros por su parte, admiten que los cuasicontratos más comunes en el Derecho Romano, eran, La Gestión Funeraria, El Enriquecimiento Injusto, La Lex Rhodia de Iactu y finalmente La Gestión de Negocios sobre la cual ahondaremos más adelante.

Según el Dr. Elmer Lizardo, La Gestión Funeraria nacía "cuando una persona acarreaba los gastos de entierro de una persona, sin estar obligado a ello. Dicha acción recibió el nombre de actio funeraria, y mediante ella, el que realizaba el entierro, reclamaba los gastos al heredero, inclusive cuando dicha gestión se hubiere hecho en contra del parecer de éste" ${ }^{30}$.

Como puede observarse en la actio funeraria un tercero acarreaba los gastos fúnebres en Garzón, Tercera edición, Universidad Externado de Colombia, Bogotá, Colombia, Página 378. 29 Lecciones de Derecho Romano, Carlos J. Medellín, Carlos Medellín F., Decimotercera edición, Editorial Temis, S.A, Sata Fe de Bogotá, Colombia, 1997, Página No 235.

30 Manual de Derecho Romano, Elmer Lizardo C., Editorial Graficentro Editores, Tegucigalpa, M.D.C, Honduras C.A., 2004, Página 301. 
nombre y representación del heredero, sin embargo éste posteriormente realizaba su cobro inmediato producto de dicha gestión.

Por su parte El Enriquecimiento Injusto, se presentaba "cuando una persona se lucraba a costa de otra, sin tener una causa jurídica.- E1 que recibía ese aumento o lucro, estaba obligado a devolverlo, por ejemplo: Cuando una persona considerándose erróneamente deudor, hacia un pago a otra persona ${ }^{31}$ ".

Otro ejemplo en que podría aplicarse dicho cuasicontrato es cuando Juan le entrega a Pedro cierta cantidad de bienes en calidad de dote a consecuencia del matrimonio de este con su sobrina Anastasia. En caso de que el matrimonio por alguna u otra razón no se llevara a cabo, Juan podría ejercitar la acción correspondiente y exigirle a Pedro la devolución del caudal entregado inicialmente.

La Lex Rhodia de Iactu, "fue tomada de la Ley de la Isla de Rhodas; cuya aplicación surgía, cuando los buques para aligerar el peso de la nave, arrojaban al mar ciertas mercancías, en perjuicio de sus dueños a efecto de poner a salvo de un peligro común.- Como era injusto que sólo los dueños de las mercancías sufrieran perjuicios, se admitió que esos daños se repartiesen entre todos los interesados, hasta la concurrencia en que se hubiesen beneficiado" 32 .

Nuestra legislación Civil, reconoce exclusivamente tres tipos de cuasicontratos: (Artículo 2303 ccc)

31 Manual de Derecho Romano, Elmer Lizardo C., Editorial Graficentro Editores, Tegucigalpa, M.D.C, Honduras C.A., 2004, Página 301.

32 Manual de Derecho Romano, Elmer Lizardo C., Editorial Graficentro Editores, Tegucigalpa, M.D.C, Honduras C.A., 2004, Página 301.
a) La agencia oficiosa;
b) El pago de lo no debido; $y$
c) La comunidad.

En definitiva, La gestión de Negocios, es el acto mediante el cual "alguien gestiona los negocios de un ausente, de un lado y otro nacen acciones llamadas Gestión de negocios. Compete la acción directa al dueño del asunto gestionado contra aquél que los gestionó, y al gestor del negocio la contraria" ${ }^{33}$.

\section{ELEMENTOS O REQUISITOS DE LA GESTION DE NEGOCIOS}

Toda figura jurídica está constituida por variados elementos que la consolidan, esto con el propósito de que surta los efectos legales esperados, y para que la negotiorum Gestio existiera se requería de al menos los requisitos subsiguientes:

1) "El Gestor debía actuar en beneficio o interés del dominus.

2) Debía obrar espontáneamente, es decir sin saberlo el dueño del negocio.

3) La Gestión debía ser útil, es decir realizada en atención a la conveniencia del dueño del negocio" ${ }^{4}$.

En otras palabras, la gestión de negocios debía hacerse en provecho del dueño del negocio y no en provecho del gestor.

De igual forma dicha gestión debía ser ignorada por completo por parte del dueño, puesto que si ésta era de su conocimiento

33 Derecho Romano para Latinoamérica, Ricardo D. RabinvichBerkman, Cevallos, Editora Jurídica, Quito, Ecuador 2006, Página 473.

34 Manual de Derecho Romano, Elmer Lizardo C., Editorial Graficentro Editores, Tegucigalpa, M.D.C, Honduras C.A., 2004, Página 300. 
el requisito no se haría efectivo, dejaría de ser negotiorum gestio, para convertirse en un mandato tácito del dueño del negocio.

Con el propósito de comprender en una forma práctica dichos elementos y de verificar los requisitos anteriores, explicaremos los mismos con el ejemplo siguiente:

"Comienza la erupción del Vesubio. Cinceles está solo en la casa de verano de Magno, tallando un bajorrelieve. La gente Huye despavorida, y él también, pero antes toma un antiguo jarrón etrusco, muy valioso, que sabe es la pieza preferida del senador, la lleva consigo, salvándola. Como Magno se beneficia, parece justo resarcirlo, por lo menos, por los gastos y daños lógicos. Cinceles para poder cargar el jarrón, ha debido dejar sus herramientas mucho más baratas. No tiene derecho a honorarios, porque no actuó por contrato, y su comportamiento fue filantrópico, no lucrativo" 35 .

Como podemos observar en el ejemplo anterior, la acción ejecutada por Cinceles pareciera desprenderse de un poder o mandato, razón por la cual se dice que las obligaciones planteadas nacen de un "casi contrato" puesto que no hay un acuerdo expreso de voluntades, sin embargo la obligación del dueño del jarrón nace porque beneficia al mismo en lugar de perjudicarlo, actuó de manera espontánea y para la conveniencia del dueño del negocio.

\section{EFECTOSDELAGESTIONDENEGOCIOS}

En las instituciones de Justiniano, en el capítulo XXVIII, se pregunta, por qué las 35 Derecho Romano para Latinoamérica, Ricardo D. RabinvichBerkman, Cevallos, Editora Jurídica, Quito, Ecuador 2006, Página 473. personas adquirimos obligaciones, a lo que éste responde, que debido a las diferentes especies de obligaciones que nacen de un contrato o como de un contrato, es preciso observar que podemos adquirir una obligación, no solo por nosotros mismos, sino también por las personas que se hallan bajo nuestra potestad, como nuestros esclavos y nuestros hijos de familia.

En analogía al punto anterior, cabe señalar que la mayoría de obligaciones nacen de un contrato o como de un contrato, la gestión de negocios, al igual que el mandato, es una fuente generadora de obligaciones, es decir, crea tanto obligaciones a cargo del gerente y pueden también nacer obligaciones a cargo del dueño, las cuales estudiaremos a continuación.

\section{OBLIGACIONES DEL GESTOR}

De conformidad a las Institutas de Justiniano, "elquedeunmodoútilha desempeñadolosnegocios de otro tiene a este por obligado, del mismo modo a su vez está obligado el primero a dar cuenta de su administración. Esta cuenta debe extenderse hasta comprender la más exacta diligencia, porque no basta la gerente poner la gestión de los negocios los cuidados que habitualmente pone en los suyos propios, siempre que hubiese otro más diligente que administrase mejor" ${ }^{36}$.

En el derecho romano, el gestor de un negocio en particular adoptaba obligaciones desde el momento en que éste decidía ejercitar dicha acción a favor del dueño, y con el siguiente ejemplo práctico comprenderemos la responsabilidad y la diligencia que el primero debe mostrar en el ejercicio de sus funciones.

36 Instituciones de Justiniano, Edición Bilingüe, Con una nota previa sobre Justiniano y las Institutas, por M. Ortolán, profesor de la facultad de derecho de París, Editorial Heliasta S.R.L., Buenos Aires Argentina, Titulo XXVII, Pág. 275-276. 
"Furio debe viajar con urgencia a Nápoles, pues su hermano agoniza allí. A la semana siguiente uno de sus arrendatarios debe pagar el alquiles del campo, y entonces Rústico, vecino y amigo de Furio, se lo recibe. Son 100 monedad de plata. Entonces aparece Nauta, que desea poner un astillero en Palermo, seguro que con su experiencia naviera tendrá gran suceso, pero necesita capital. Rustico le presta las 100 monedas de Furio y otras 100 suyas. Al cabo de un año Nauta, convertido en exitoso empresario, le entrega 224 monedas. Regresa Furio, y Rústico le rinde cuentas, de las 112 monedas que le corresponden, descuenta el gasto de dos viajes que debió hacer a Palermo; restan 108 monedas de plata.

Furio no está satisfecho: "!Si en vez de prestarle a Nauta hubieres puesto ese dinero con el banquero, hubieras obtenido el doble de usuras!. "No traté tu dinero en forma diferente del mio propio, se defiende Rústico, "yo también presté mis monedad a Nauta". ${ }^{37}$

De acuerdo a las Instituciones de Justiniano Rústico tuvo que resarcir a Furio por los intereses quedejó de percibirbajoelargumentodeque Rústico no fue diligente en la administración del negocio a lo cual tuvo que responder hasta la culpa leve.

De igual forma, es importante hacer resaltar que la responsabilidad adquirida por el gestor varía dependiendo del resultado y de la intención que se perseguía al momento de intervenir en la misma, verbigracia:

"Mientras Nauta y su gente ofrecen un sacrifico a Neptuno en su templo, un rayo cae sobre el mercurio. Casio y sus hijos que pasan por ahí, se lanzan a apagar el incendio. $\mathrm{Si}$, por no

37 Derecho Romano para Latinoamérica, Ricardo D. Rabinvich-Berkman, Cevallos, Editora Jurídica, Quito, Ecuador 2006, Página 473-474. tener experiencia como bomberos, el fuego tarda en extinguirse, y el daño es grande, no responden, Pero responderían si, cuando otros marinos vinieron a ayudar, Casio les gritó “!Váyanse, nos arreglamos solos!”. Y más aún si, como Casio desea un toga nueva, se pone la suya para combatir la llamas, sabiendo que se arruinará, para luego exigir a Nauta otra" ${ }^{30}$

No obstante, si la intención de quien decide lanzarse a defender los bienes ajenos, es de buena fé, éste no debería ser tratado con severidad, puesto que la intención al momento de verificarse el siniestro, respondía a un acto humanitario y de buena voluntad.

En analogía a lo estipulado en nuestro Código Civil Colombiano, el artículo 2306, determina que se "debe, en consecuencia, emplear en la gestión los cuidados de un buen padre de familia; pero su responsabilidad podrá ser mayor o menor en razón de las circunstancias que le hayan determinado a la gestión.

Si se ha hecho cargo de ella para salvar de un peligro inminente los intereses ajenos, sólo es responsable del dolo o de la culpa grave; y si ha tomado voluntariamente la gestión, es responsable hasta de la culpa leve; salvo que se haya ofrecido a ella, impidiendo que otros lo hiciesen, pues en este caso responderá de toda culpa." ${ }^{38}$.

El gestor, debe asimismo, encargarse de todas las dependencias del negocio, y continuar en la gestión hasta que el interesado pueda tomarla o encargarla a otro. Si el interesado fallece, deberá continuar en la gestión hasta que los herederos dispongan. (Artículo 2307 CCC).

38 Código Civil Colombiano, Luis cesar Pereira Monsalve, 1996, Editorial Poligráficas, Medellín, Colombia. Artículo 2305, pagina, 546.

Revista de Derecho. Vol. 42, No. 1, Año 2021 -197 
En realidad es impresionante conocer la forma tan sabia en que la negotiarum gestorum era dilucidada por los romanos, y la similitud con el derecho civil actual, pero más impactante aún, la forma en que éstos (romanos) solían resolver los entuertos desplegados a través de casos prácticos, y las diversas soluciones en que ésta figura podía ser disipada.

\section{OBLIGACIONES DEL DUEÑO (DOMINUS)}

Mucho hemos hablado ya, acerca de las obligaciones del gestor para con el dueño del negocio, la cuales se comparan a las de un buen administrador, sin embargo es justo y necesario adentrar en aquellas obligaciones que adopta el dominus o dueño del negocio jurídico.

Una de las principales obligaciones que tiene el dominus es la de "reembolsar al gestor todo gasto útil invertido en la gestión, indemnizarle de todo perjuicio, y si se ha hecho deudor con motivo de la gestión, debía revelarlo de la deuda tomándola a su cargo ${ }^{39}$ ".

Según Ulpiano, "el dueño está obligado a indemnizar al gerente de sus gastos, pero solo si eran útiles en el momento en que se hicieron" ${ }^{40}$.

Por su parte, nuestro código civil preceptúa en el artículo 2312 que el gerente no puede intentar acción alguna contra el interesado, sin que preceda una cuenta regular de la gestión, con documentos justificativos o pruebas equivalentes.

Así las cosas, para que el gerente del negocio pueda interponer la acción jurídica correspondiente ante los juzgados o tribunales competentes, requerirá éste de cuantas pruebas 39 Lecciones de Derecho Romano, Carlos J. Medellín, Carlos Medellín F., Decimocuarta edición, Editorial Temis, S.A, Santa Fe de Bogotá, Colombia, 2000, Página No 263.

40 Ulpiano, L. 10, 1, D. , de negot. Gest. III, 5. documentales sean necesarias, para justificar los gastos económicos en que éste incurrió, al momento de interferir como gestor.

Art. 2308. Si el negocio ha sido bien administrado, cumplirá el interesado las obligaciones que el gerente ha contraído en la gestión, y le reembolsará las expensas útiles o necesarias.

El interesado no es obligado a pagar salario alguno al gerente. (Artículo 2308 CCC)

\section{FORMASDEEXIGIRSUCUMPLIMIENTO}

"Pero así como el que de un modo útil ha desempeñado los negocios de otro tiene a éste por obligado, del mismo modo a su vez está obligado el primero a dar cuenta de su administración". ${ }^{41}$

En el derecho romano, "las obligaciones a cargo del gestor se hacían judicialmente efectivas por medio de la acción de la negotiorum gestorum directa, o sea del dominus contra el gestor; y las obligaciones que podían surgir a cargo del dominus y a favor del gestor se hacían efectivas por medio de la acción negotiorum gestorum contraria, o sea del gestor contra el dominus" ${ }^{42}$.

De lo anterior, podríamos ultimar que la acción directa para actuar legal o judicialmente compete al dueño del negocio contra aquél que los gestionó, y al gestor del negocio la acción contraria.

41 Instituciones de Justiniano, Edición Bilingüe, Con una nota previa sobre Justiniano y las Institutas, por M. Ortolán, profesor de la facultad de derecho de París, Editorial Heliasta S.R.L., Buenos Aires Argentina, Titulo XXVII, Pág. 275.

42 Lecciones de Derecho Romano, Carlos J. Medellín, Carlos Medellín F., Decimocuarta edición, Editorial Temis, S.A, Sata Fe de Bogotá, Colombia, 2000, Página No 263. 
No obstante, partiendo de la premisa que las acciones que dan origen a la negotiorum gestorum no nacen de un contrato propiamente dicho, podríamos decir entonces que, "dichas acciones solo nacen cuando alguien se introduce $\sin$ mandato en negocios ajenos" ${ }^{43}$.

Un típico ejemplo en cuanto a la forma accionar lo constituye la acción funeraria, ya que dada la importancia que para el romano tienen los rituales póstumos, quien se hace cargo de los gastos que se irrogan, sin ser heredero del muerto, goza de esta acción los sucesores de la herencia. Por aplicación de los principios generales de la gestión, el funeral debe haberse solventado con ánimo de concretar un negocio ajeno, no "por causa de piedad”. Como esta prueba es diabólica, la compilación permite al juez manejarse con libertad, propiciando el resarcimiento" ${ }^{44}$.

Por otra parte, según Eduardo Álvarez Correa, para que el agente o gestor goce de la acción de agencia oficiosa en contra del beneficiado y recupere sus gastos, debería al menos reunir los siguientes requisitos:

1.- El acto cumplido por el agente debe ser razonable, es decir un acto que una persona razonable, prudente, adelantaría según las circunstancias.

Un ejemplo de ello podría ser, el techo del vecino ausente está por caerse, poniendo en peligro los bienes dentro de la casa: el agente lo repara o lo hace reparar.

43 Derecho Romano para Latinoamérica, Ricardo D. RabinvichBerkman, Cevallos, Editora Jurídica, Quito, Ecuador 2006, Página 473.

44 Derecho Romano para Latinoamérica, Ricardo D. RabinvichBerkman, Cevallos, Editora Jurídica, Quito, Ecuador 2006, Página 475.
2.- El acto debe cumplirse en beneficio del tercero, y no por el mero beneficio del agente.

3.- El acto debe tener una utilidad, o haber sido aceptado por el beneficiado.

Por utilidad se entiende algo distinto a lo inútil, como puede ser una construcción lujosa que no tiene verdadera utilidad. Si lo hecho no tiene utilidad, pero es aceptado por el beneficiado, el agente podrá reclamar el reembolso de sus gastos.

4.- El beneficiado no debió haber prohibido el acto, ni pudo haber sido una donación por parte del agente o el cumplimiento de una obligación preexistente.

En todo caso, si el beneficiado dio su acuerdo antes de que el agente hiciese algo, se trataría de un mandato y no de agencia oficiosa.

En último lugar, el código civil colombiano preceptúa que "El que administra un negocio ajeno contra la expresa prohibición del interesado no tiene demanda contra él, sino en cuanto esa gestión le hubiere sido efectivamente útil, y existiere la utilidad al tiempo de la demanda, por ejemplo, si de la gestión ha resultado la extinción de una deuda que, sin ella, hubiere debido pagar el interesado.

El juez, sin embargo, concederá en este caso al interesado el plazo que pida para el pago de la demanda, y que por las circunstancias del demandado parezca equitativo”. (Art. 2309 CCC)

\section{DIFERENCIA ENTRE MANDATO Y NEGOTIORUM GESTORUM}


"Qui aliena negotia mandatu domini administrat"45

Ante el inminente desconcierto entre la gestión de negocios y el mandato propiamente dicho, se torna justo y necesario realizar una diferenciación entre ambas figuras jurídicas.

En el Derecho romano, "Las obligaciones nacidas de este cuasicontrato (negotiurum gestium) eran parecidas a las del mandato ${ }^{46}$ "

En páginas anteriores nos hemos encargado de conceptualizar la figura de la gestión de negocios, sin embargo, nos enfocaremos en esta parte a definir el concepto que gira en torno al mandato y a establecer diferencias.

El mandato en el derecho romano es un "contrato simplemente consensual, sinalagmático imperfecto, y de buena fe, por el cual una persona encargaba a otra que aceptaba, la realización gratuita de una o más operaciones que tuvieran un interés pecuniario para el mandante ${ }^{47}$.

El mandato "es un contrato por el cual una persona da encargo a otra persona, que acepta, de realizar gratuitamente un acto determinado o un conjunto de operaciones" 48

En nuestra legislación Civil colombiana un mandato se define, "como un contrato en que una persona confía la gestión de uno o más negocios

45 El Digesto 3, 3, 1.

46 Lecciones de Derecho Romano, Carlos J. Medellín, Carlos Medellín F., Decimocuarta edición, Editorial Temis, S.A, Sata Fe de Bogotá, Colombia, 2000, Página No 263.

47 Lecciones de Derecho Romano, Carlos J. Medellin, Carlos Medellin F., Decimotercera edición, Editorial Temis, S.A, Sata Fe de Bogotá, Colombia, 1997, Página No 258.

48 Mandatum viene de manum dare, dar la mano en señal de confianza y, por extensión, dar poder ( Plauto, Captiv. Act. II, SC. 3) a otra, que se hace cargo de ellos por cuenta y riesgo de la primera ${ }^{49}$ ".

A medida que avanzamos en el presente estudio, nos damos cuenta que la gestión de negocios tiende a ser confundida con la figura del mandato.

Tal y como lo relacionábamos en la introducción del presente trabajo investigativo, ante nuestras oficinas registrales ingresaban testimonios de escrituras públicas en donde un gestor comparecía en algunas ocasiones, aceptando y en otras, otorgando en venta un inmueble a favor de un tercero (comprador).

Cuando un gestor aparecía en calidad de otorgante o vendedor, procedíamos a denegar el registro de dicha venta, amparados en que, el compareciente que actuaba como gestor no debía aparecer como tal, sino como representante del legítimo dueño, requiriendo para ello un poder (mandato) en donde se le confirieran amplias facultades para administrar sus negocios y consumar así dicha venta.

Podemos observar que las obligaciones nacidas de la gestión de negocios, tienden a ser confundidas con la figura del mandato, sin embargo es claro que en la gestión no existe consentimiento alguno, mientras que en el mandato si lo hay.

De conformidad a lo regulado en el derecho romano, un gestor podría actuar en tal condición, siempre y cuando la adquisición del inmueble objeto de venta sea de utilidad y beneficio para el dominus, de lo contrario éste podría ejercitar la acción de negotiorum gestorum directa contra éste, sin embargo para que un gestor pueda otorgar en venta dicho inmueble, no cabría dicha 49 Código Civil Colombiano, Versión Actualizada, Legis Editorial, 2010, Bogotá, Colombia, articulo 2142 
figura, requiriendo para ello un mandato especial, en donde se le faculte, no como gestor sino más bien como mandatario a efectuar esa venta.

En cuanto a los compromisos desencadenantes entre ambas figuras jurídicas, El Código Civil Colombiano establece en su artículo 2305, que "las obligaciones del agente oficioso o gerente son las mismas que las del mandatario”.

Por su parte, el Código de comercio colombiano es otra compilación en donde se contempla a la gestión de negocios como figura legal (artículo 235), y por ende existe un ligero riesgo de ser confundida con la Fiducia mercantily el mandato propiamente dicho, siendo la "fiducia un negocio jurídico típico bien distinto del mandato y por ello el fiduciario obra en nombre propio comprometiendo los bienes afectados sin que sus actos se puedan entender como realizados por cuenta de otro ${ }^{50}$.

Según, Arias García "la expresión "por cuenta de otro" no tiene asidero en la gestión fiduciaria porque ésta no implica un fenómeno representativo y está bien alejada de figuras como la estipulación para otros, la estipulación por otros, la gestión de negocios y el mandato" de conformidad con el artículo 1235 del Código de Comercio Colombiano" ${ }^{43}$.

Claro está que las obligaciones emanadas entre gestión de negocios y mandato son inmediatamente vinculantes, sin embargo, ambas figuras se diferencian una de la otra en que, en la gestión no hay consentimiento por parte del dueño, mientras que en el mandato si existe dicho consentimiento como tal, sea éste expreso o tácito.

50 El Fiduciario en la Legislación Mercantil Colombiana, Fernando Arias García, Revista Internauta de Práctica Jurídica. Núm 20 Julio Diciembre 2007, Pág. 2.

\section{CONCLUSIONES}

- Lagestión de negocios como un cuasicontrato, se asemeja a un contrato propiamente dicho, en que ambos generan obligaciones y traen consigo hechos semejantes o parecidos, sin embargo, se diferencian el uno del otro, en que los cuasicontratos carecen del elemento consensual (consentimiento).

- Partiendo de la premisa que la mayoría de las obligaciones nacen de un contrato o como de un contrato, la gestión de negocios, al igual que el mandato, es una fuente generadora de obligaciones, es decir, crea diversas obligaciones a cargo del gerente y recíprocamente, obligaciones a cargo del dueño.

- La obligación de un gestor se compara a la de un buen administrador, quién al no ser diligente en la administración de este, se le podrán deducir la responsabilidad civil respondiendo hasta la culpa leve por su inadecuada forma de actuar.

- Entre otros, uno de los principales compromisos imputables al dominus es la de reembolsar al gestor todo gasto en el que éste pudo haber incurrido durante la gestión del negocio, e indemnizarle de todo perjuicio amparado en las pruebas documentales correspondientes.

- De conformidad a lo promulgado en el derecho romano, un gestor podría actuar en tal condición, siempre y cuando la adquisición del inmueble objeto de venta sea de utilidad y beneficio para el dominus, de lo contrario éste podría ejercitar la acción de negotiorum gestorum directa contra éste, sin 
embargo para que un gestor pueda otorgar en venta dicho inmueble, no cabría dicha figura, requiriendo para ello un mandato especial, en donde se le faculte, no como gestor sino más bien como mandatario a efectuar esa venta.

- En el derecho romano la figura de la gestión oficiosa era utilizada en favor de un tercero llamado dueño, y esta no era esgrimida a contrario sensu, para otorgar en venta los bienes de ese dueño en su condición de gestor, para lo cual tendría que necesitar un mandato con facultades especiales y efectuar así dicho negocio jurídico.

- La acción directa para actuar legal o judicialmente compete al dueño del negocio contra aquél que los gestionó, y al gestor del negocio la acción contraria, para ejercitar el mismo derecho.

\section{BIBLIOGRAFIA}

- Bustos, Alicia M. Oviedo (1984) Gestión de Negocios, Editorial Astrea, Primera Edición, Lavalle, Buenos Aires, Argentina.

- De Semo Giorgio (1961), La Gestión de Negocios Ajenos en la teoría y en la práctica, tr. J. Rodríguez del Barco, Madrid, Revista de Derecho privado.

- Krieguel, Hermman, Osenbruggen, Hermman Osenbruggen (1889) Digesto, Libro III, tit. V. Ley I., cuerpo del derecho civil romano, traducido al castellano del latín, publicado por los hermanos Krieguel, Hermman Osenbruggen, Barcelona Jaime Molinas.
- El Digesto de Justiniano, Tomo III, Versión Castellana por A. D'ors, F. Fernando-Tejero, Fuenteseca, M. García-Garrido y J. Burillo, Libro XLIV, tit. VII. Ley 5, Editorial aranzadi, Pamplona.

- Garzón Fabio Espitia (2004) Historia del Derecho Romano,, Tercera edición, Universidad Externado de Colombia, Bogotá, Colombia.

- Álvarez Correa Eduardo, (1979) Curso de Derecho Romano, Primera edición, Editorial Puma Ltda, Bogotá, Colombia.

- Instituciones de Justiniano, Edición Bilingüe, Con una nota previa sobre Justiniano y las Institutas, por M. Ortolán, profesor de la facultad de derecho de París, Editorial Heliasta S.R.L., Buenos Aires Argentina, Titulo XXVII.

- Caramés Ferro, José M. (1953) Instituciones de Derecho privado Romano, Bs. As., Perrot, 1953, Buenos Aires Argentina.

- Vélez, Lucrecio Jaramillo (1986) Historia del Derecho Romano, Sistema de Derecho Privado, , Cuarta Edición, Señal Editora.

- Medellín Carlos J., Carlos (1997) Lecciones de Derecho Romano Decimotercera edición, Editorial Temis, S.A, Sata Fe de Bogotá, Colombia.

- Petit, Eugene (1985) Tratado Elemental de Derecho Romano, , Editorial Albatros, Buenos Aires Argentina.

- Código Civil Colombiano (2010), Versión Actualizada, Legis Editorial, 2010, Bogotá, Colombia. 
- Muñoz López, Luis Alfonso (2007)

Derecho Romano comparado con el

derecho colombiano, Quinta edición,

Editorial Temis S.A., Bogotá, Colombia.

- Lizardo C., Elmer (2004) Manual de

Derecho Romano, Editorial Graficentro

Editores, Tegucigalpa, M.D.C, Honduras C.A..

- Rabinvich-Berkman, Ricardo D. (2006), Derecho Romano para Latinoamérica, Editora Jurídica, Quito, Ecuador.

- Instituciones de Justiniano, Edición Bilingüe, Con una nota previa sobre Justiniano y las Institutas, por M. Ortolán, profesor de la facultad de derecho de París, Editorial Heliasta S.R.L., Buenos Aires Argentina, Titulo XXVII.

- Pereira Monsalve, Luis cesar (1996)

Código Civil Colombiano, Editorial Poligráficas, Medellín, Colombia.

- J. Medellín, Carlos, Medellín F, Carlos (2000) Lecciones de Derecho Romano, Decimocuarta edición, Editorial Temis, S.A, Santa Fe de Bogotá, Colombia.

- Arias García, Fernando (2007) El Fiduciario en la Legislación Mercantil Colombiana, Revista Internauta de Práctica Jurídica. Número 20 Julio Diciembre 2007. 